\title{
Examining soil carbon uncertainty in a global model: response of microbial decomposition to temperature, moisture and nutrient limitation
}

\author{
J.-F. Exbrayat ${ }^{1}$, A. J. Pitman ${ }^{1}$, Q. Zhang ${ }^{2}$, G. Abramowitz ${ }^{1}$, and Y.-P. Wang ${ }^{3}$ \\ ${ }^{1}$ ARC Centre of Excellence for Climate System Science and Climate Change Research Centre, University of New South \\ Wales, Sydney, New South Wales, Australia \\ ${ }^{2}$ College of Global Change and Earth System Science, Beijing Normal University, Beijing, China \\ ${ }^{3}$ The Centre for Australian Weather and Climate Research, CSIRO Marine and Atmospheric Research, Private Bag 1, \\ Aspendale, Victoria, Australia \\ Correspondence to: J.-F. Exbrayat (j.exbrayat@unsw.edu.au)
}

Received: 5 June 2013 - Published in Biogeosciences Discuss.: 24 June 2013

Revised: 3 October 2013 - Accepted: 11 October 2013 - Published: 8 November 2013

\begin{abstract}
Reliable projections of future climate require land-atmosphere carbon (C) fluxes to be represented realistically in Earth system models (ESMs). There are several sources of uncertainty in how carbon is parameterised in these models. First, while interactions between the $\mathrm{C}$, nitrogen $(\mathrm{N})$ and phosphorus $(\mathrm{P})$ cycles have been implemented in some models, these lead to diverse changes in land-atmosphere fluxes. Second, while the first-order parameterisation of soil organic matter decomposition is similar between models, formulations of the control of the soil physical state on microbial activity vary widely. For the first time, we address these sources of uncertainty simultaneously by implementing three soil moisture and three soil temperature respiration functions in an ESM that can be run with three degrees of biogeochemical nutrient limitation (C-only, $\mathrm{C}$ and $\mathrm{N}$, and $\mathrm{C}$ and $\mathrm{N}$ and $\mathrm{P}$ ). All 27 possible combinations of response functions and biogeochemical mode are equilibrated before transient historical (1850-2005) simulations are performed. As expected, implementing $\mathrm{N}$ and $\mathrm{P}$ limitation reduces the land carbon sink, transforming some regional sinks into net sources over the historical period. Meanwhile, regardless of which nutrient mode is used, various combinations of response functions imply a two-fold difference in the net ecosystem accumulation and a four-fold difference in equilibrated total soil $\mathrm{C}$. We further show that regions with initially larger pools are more likely to become carbon sources, especially when nutrient availability limits the
\end{abstract}

response of primary production to increasing atmospheric $\mathrm{CO}_{2}$. Simulating changes in soil $\mathrm{C}$ content therefore critically depends on both nutrient limitation and the choice of respiration functions.

\section{Introduction}

A major step in the transition from climate system models to Earth system models (ESMs) is the inclusion of additional biogeochemical processes. If the carbon (C) cycle was in equilibrium this would be an academic exercise, but how terrestrial $\mathrm{C}$ stores respond to warming resulting from human emissions of atmospheric carbon dioxide $\left(\mathrm{CO}_{2}\right)$ is of critical importance. Vegetation stores around 450-650 Pg C (Prentice et al., 2001), while soils store 1500-2400 Pg C (Batjes, 1996), with additional carbon stored in peatland and wetland soils ( $\sim 530$ Pg C; Bridgham et al., 2006) and in permafrost $(\sim 1670$ Pg C; Tarnocai et al., 2009). If vegetation and soil processes respond to global warming by increasing the terrestrial C sink, this could help offset human emissions. Conversely, any decrease in the magnitude of the terrestrial sink, or any progressive loss of stored terrestrial $\mathrm{C}$ would provide a positive feedback on global warming.

Our current understanding is that human-induced increases in atmospheric $\mathrm{CO}_{2}$ likely enhanced the terrestrial $\mathrm{C}$ uptake during the 20th century (Sarmiento et al., 2010) more 
than global warming has enhanced microbial decomposition and corresponding release by heterotrophic respiration $\left(R_{\mathrm{h}}\right)$. It is, however, uncertain whether this increase can be sustained into the future (McCarthy et al., 2010; Norby et al., 2010; Zak et al., 2011). Indeed, some ecosystems appear to lack any significant response to increasing atmospheric $\mathrm{CO}_{2}$ (Adair et al., 2009; Bader et al., 2009; Norby et al., 2010). According to previous modelling studies, any additional terrestrial carbon uptake linked to $\mathrm{CO}_{2}$ fertilisation is also likely to be more than offset in the future by the increase in $R_{\mathrm{h}}$ following warming (Cox et al., 2000). This extra C released into the atmosphere would further accelerate global warming (Kirschbaum, 2000), and a climate-change-driven acceleration of soil organic $\mathrm{C}$ decomposition rates would therefore represent a positive feedback on climate (Kirschbaum, 2004). However, there is a lack of agreement between modelbased estimates of when and at what rate soil C storage might begin to decline (Friedlingstein et al., 2006). Further, net primary production (NPP) and microbial decomposition are controlled by the availability of nitrogen $(\mathrm{N})$ and phosphorus $(\mathrm{P})$, with $\mathrm{N}$ limitation tending to dominate in temperate and boreal ecosystems, and $\mathrm{P}$ limitation tending to dominate in the tropics (Luo et al., 2004; Vitousek et al., 2010; Wang et al., 2010; Goll et al., 2012). Recently, there has been an extensive effort to implement these processes in terrestrial ecosystem models (e.g. Thornton et al., 2007; Sokolov et al., 2008; Yang et al., 2009; Wang et al., 2010; Zaehle and Friend, 2010; Esser et al, 2011; Menge et al., 2012). Generally, adding $\mathrm{N}$ limitation reduces the simulated global land C uptake during the 20th century relative to non-nutrientlimited simulations. Early results suggest $\mathrm{P}$ limitation makes a negligible difference to the global terrestrial carbon uptake, but can introduce very large regional differences particularly in the tropics (Zhang et al., 2011). However, despite the recognition of the importance of interactions between these biogeochemical cycles, interactions between terrestrial $\mathrm{C}$ and $\mathrm{N}$ cycles are represented in just three of the ESMs used in the Coupled Model Intercomparison Project, Phase 5 (CMIP5; Taylor et al., 2012), among which two models use the Community Land Model as their terrestrial component: CCSM4 and NorESM (Todd-Brown et al., 2013). Meanwhile, the terrestrial P cycle is omitted in all CMIP5 simulations (ToddBrown et al., 2013). This introduces critical uncertainties in projections as nutrient limitation prevents vegetation growth at the rate allowed for by $\mathrm{CO}_{2}$ fertilisation in different ways between models.

An additional uncertainty resides in the current parameterisation of microbial decomposition and corresponding $R_{\mathrm{h}}$ in ESMs. So far, all CMIP5 models represent decomposition as a first-order process (Todd-Brown et al., 2013) in which instantaneous soil moisture and soil temperature are used to adjust a time-invariant decay rate that is applied to the amount of substrate available (i.e. C pool size). Put in a mathematical way, at each time step, the actual amount of microbial decomposition $D_{\mathrm{m}}$ in a specific C pool is calculated as

$D_{\mathrm{m}}=k \times f_{\mathrm{W}}\left(\theta_{\mathrm{s}}\right) \times f_{\mathrm{T}}\left(T_{\mathrm{s}}\right) \times C_{\mathrm{s}}$,

with $k$ the reference decay rate that is scaled by $f_{\mathrm{T}}$, a function of soil temperature $T_{\mathrm{s}}$, and by $f_{\mathrm{W}}$, a function of soil moisture $\theta_{\mathrm{s}}$ (usually expressed as a fraction of water saturation; Moyano et al., 2012), and $C_{\mathrm{S}}$ is the amount of $\mathrm{C}$ in the pool. The product $f_{\mathrm{W}}\left(\theta_{\mathrm{s}}\right) \times f_{\mathrm{T}}\left(T_{\mathrm{S}}\right)$ is sometimes referred to as an environmental scalar. Part of the decomposition is emitted as $\mathrm{CO}_{2}$, and this flux corresponds to $R_{\mathrm{h}}$, while the rest is typically assigned to different soil $\mathrm{C}$ pools. The lack of physiological control has been recently identified as being inconsistent with our current understanding of decomposition process (e.g. Allison et al., 2010; Schmidt et al., 2011). Nevertheless, first-order kinetics applied to a succession of $\mathrm{C}$ pools with different residence time are able to explain complex processes including the apparent thermal acclimation of decomposers to warming (Luo et al., 2001) with a quick depletion in the most labile pools (Kirschbaum, 2004; Knorr et al., 2005). However, in current models, simple changes in the formulation of $f_{\mathrm{W}}$, the soil moisture-respiration function, and $f_{\mathrm{T}}$, the soil temperature-respiration function can have a major influence on $R_{\mathrm{h}}$ (Falloon et al., 2011; Exbrayat et al., 2013a). These impacts on $R_{\mathrm{h}}$ can determine whether soil carbon stores increase or decrease for the same NPP, meaning they control whether the soil will remain a sink or convert to a source of $\mathrm{CO}_{2}$ in the future. The various representations of $R_{\mathrm{h}}$ are also responsible, at least in part, for the six-fold range in soil $\mathrm{C}$ achieved by CMIP5 simulations at the end of the 20th century in response to a three-fold range in NPP (Todd-Brown et al., 2013).

In this paper, we address two questions arising from the current parameterisation of the land carbon cycle. First, how do $\mathrm{N}$ and $\mathrm{P}$ limitations on plant productivity affect the response of soil C to different combinations of $f_{\mathrm{W}}$ and $f_{\mathrm{T}}$ over the 20th century? Second, through which mechanism is $R_{\mathrm{h}}$ sensitive to the formulation of its response to changes in soil moisture and soil temperature? We explore these two sources of uncertainty in combination and quantify their influence on both equilibrated states and the response of the terrestrial component of a global ESM to the historical increase in atmospheric $\mathrm{CO}_{2}$ and associated warming. Therefore, we examine at global and regional scales how the simulated historical carbon cycle is affected by the way soil moisture and soil temperature control $R_{\mathrm{h}}$ using three formulations of $f_{\mathrm{W}}$, three formulations of $f_{\mathrm{T}}$, and $\mathrm{N}$ and $\mathrm{P}$ limitation.

\section{Methods}

\subsection{Modelling system}

We use the Carnegie-Ames-Stanford Approach with a Carbon-Nitrogen-Phosphorus (CASA-CNP) land biogeochemical model (Wang et al., 2010) coupled with the 
Table 1. Formulations of $f_{\mathrm{W}}$ implemented in the CASA-CNP model ( $\theta_{\mathrm{s}}$ : soil moisture; $\theta_{\mathrm{wilt}}:$ moisture at wilting point; $\theta_{\mathrm{fc}}:$ moisture at field capacity; $\theta_{\text {opt }}$ : optimum moisture; $\theta_{\text {lopt }}$ : lower optimal moisture - all expressed relative to moisture at saturation).

\begin{tabular}{ll}
\hline Function & Equation \\
\hline CASA-CNP & $f_{\mathrm{W}}\left(\theta_{\mathrm{s}}\right)=\left(\frac{\theta_{\mathrm{s}}-1.70}{0.55-1.70}\right)^{6.6481} \times\left(\frac{\theta_{\mathrm{s}}+0.007}{0.55+0.007}\right)^{3.22}$ \\
\hline SOILN & $\theta_{\mathrm{opt}}=0.92$ \\
& $\theta_{\mathrm{lopt}}=\theta_{\text {wilt }}+0.1$ \\
& if $\theta_{\mathrm{s}}>\theta_{\text {opt }}, \quad f_{\mathrm{W}}\left(\theta_{\mathrm{s}}\right)=0.2+0.8 \cdot \frac{\left(1-\theta_{\mathrm{s}}\right)}{\left(1-\theta_{\text {opt }}\right)}$ \\
& if $\theta_{\text {lopt }} \leq \theta_{\mathrm{s}} \leq \theta_{\text {opt }}, \quad f_{\mathrm{W}}\left(\theta_{\mathrm{s}}\right)=1$ \\
& if $\theta_{\text {wilt }} \leq \theta_{\mathrm{s}} \leq \theta_{\mathrm{lopt}}, \quad f_{\mathrm{W}}\left(\theta_{\mathrm{s}}\right)=\frac{\theta_{\mathrm{s}}-\theta_{\text {wilt }}}{\theta_{\text {lopt }}-\theta_{\text {wilt }}}$ \\
& if $\theta_{\mathrm{s}}<\theta_{\text {wilt }}, \quad f_{\mathrm{W}}\left(\theta_{\mathrm{s}}\right)=0$ \\
\hline TRIFFID & $\theta_{\text {opt }}=0.5 \cdot\left(1+\theta_{\text {wilt }}\right)$ \\
& if $\theta_{\mathrm{s}}>\theta_{\text {opt }}, \quad f_{\mathrm{W}}\left(\theta_{\mathrm{s}}\right)=1-0.8 \cdot\left(\theta_{\mathrm{s}}-\theta_{\text {opt }}\right)$ \\
& if $\theta_{\text {wilt }} \leq \theta_{\mathrm{s}} \leq \theta_{\text {opt }}, \quad f_{\mathrm{W}}\left(\theta_{\mathrm{s}}\right)=0.2+0.8 \cdot \frac{\left(\theta_{\mathrm{s}}-\theta_{\text {wilt }}\right)}{\left(\theta_{\text {opt }}-\theta_{\text {wilt }}\right)}$ \\
& if $\theta_{\mathrm{s}}<\theta_{\text {wilt }}, \quad f_{\mathrm{W}}\left(\theta_{\mathrm{s}}\right)=0.2$ \\
\hline
\end{tabular}

Community Atmosphere Biosphere Land Exchange (CABLE) land surface model (Wang et al., 2011). CASA-CNP simulates the turnover of terrestrial carbon based on three vegetation, three litter and three soil pools. Soil $R_{\mathrm{h}}$ sums the $\mathrm{CO}_{2}$ fluxes from the decomposition of litter and soil carbon. In each pool, $R_{\mathrm{h}}$ is represented as a first-order process that depends on substrate availability, soil moisture and soil temperature, and these two latter terms are calculated in CABLE in response to meteorological forcing. CASACNP can be run in a carbon-only (C-only), $\mathrm{C}$ with nitrogen limitation $(\mathrm{CN})$, and $\mathrm{CN}$ with phosphorus limitations (CNP) mode. Effectively, NPP is limited by the concentration of N (in CN mode) as well as P (in CNP mode) in leaves. The uptake of mineral $\mathrm{N}$ and labile $\mathrm{P}$ depends on their availability in soils, while mineralisation rates are tightly linked to $\mathrm{C}$ decomposition rates (Wang et al., 2010). We use parameter values for CASA-CNP that were previously reported by Wang et al. (2010). The CABLE + CASA-CNP terrestrial system has been coupled to the CSIRO Mk3L climate system model (Phipps et al., 2011; Zhang et al., 2011). The relatively coarse resolution of the model $\left(5.6^{\circ}\right.$ lat. $3.2^{\circ}$ long.) makes it a computationally efficient candidate of choice to create multiple simulations for sensitivity analyses, while simulated climate is still representative of the historical period (Phipps et al., 2011). Since we address the terrestrial carbon balance, our setup uses prescribed sea surface temperatures (SSTs) from the CSIRO Mk3.6 model (Rotstayn et al., 2012) using CMIP5 historical forcing data from 1850 to 2005 (Taylor et al., 2012) that were re-gridded at the resolution of Mk3L.

\subsection{Model versions}

To examine the uncertainty linked to the choice of biophysical response functions, three variations of $f_{\mathrm{W}}$ and three variations of $f_{\mathrm{T}}$ were implemented in the CASA-CNP model
(Fig. 1). These represent the key features of a larger suite of functions used in previous offline site-scale studies with the CABLE + CASA-CNP modelling system (Exbrayat et al., 2013a), and their exact formulation can be found in Table 1 and Table 2 for $f_{\mathrm{W}}$ and $f_{\mathrm{T}}$, respectively. As shown in Fig. 1, the general consensus is that soil respiration is enhanced by intermediate moisture associated with warm temperatures. For example, while the bell-shaped $f_{\mathrm{W}}$ used in CASA-CNP simulates a smooth response of soil respiration to drying conditions, SOILN (Jansson and Berg, 1985) and TRIFFID (Cox, 2001) predict a constantly null or lowmoisture adjustment below wilting point, respectively. Further, SOILN considers a whole range of optimal moisture conditions, while the two other formulations of $f_{\mathrm{W}}$ both have a single, though different, optimal moisture. In saturated conditions, TRIFFID allows a higher respiration rate than the other $f_{\mathrm{W}}$. Comparing the temperature functions $f_{\mathrm{T}}$, CASA-CNP allows higher respiration rate for temperatures below $+10^{\circ} \mathrm{C}$, while $\mathrm{K} 1995$ (Kirschbaum, 1995) is higher than the others between $+10^{\circ} \mathrm{C}$ and $+40^{\circ} \mathrm{C}$. Finally PnET (Aber et al., 1997) displays the highest temperature-based adjustment of $R_{\mathrm{h}}$ for soil temperatures above $+40^{\circ} \mathrm{C}$. Interestingly, while CASA-CNP and PnET continue to increase, K1995 starts decreasing above $+37^{\circ} \mathrm{C}$.

\subsection{Experiments}

Simulations were performed using the modelling system described in section 2.1 with each combination of a moisture function, a temperature function and a nutrient limitation mode (C-only, $\mathrm{CN}$ and $\mathrm{CNP}$ ): a total of 27 model versions. Following Zhang et al. (2011), we first initialised the 27 model versions offline using constant pre-industrial $\mathrm{CO}_{2}(284.7 \mathrm{ppmv})$ and $5 \mathrm{yr}$ of previously equilibrated climatology and gross primary production sourced from a 
Table 2. Formulations of $f_{\mathrm{T}}$ implemented in the CASA-CNP model $\left(T_{\mathrm{s}}\right.$ : soil temperature in $\left.{ }^{\circ} \mathrm{C}\right)$.

\begin{tabular}{ll}
\hline Function & Equation \\
\hline CASA-CNP & $f_{\mathrm{T}}\left(T_{\mathrm{S}}\right)=1.72^{\left(0.1 \cdot\left(T_{\mathrm{S}}-35\right)\right)}$ \\
\hline K1995* & $f_{\mathrm{T}}\left(T_{\mathrm{S}}\right)=$ \\
& $\exp \left(-3.764+0.204 \cdot T_{\mathrm{S}} \cdot\left(1-\frac{0.5 \cdot T_{\mathrm{S}}}{36.9}\right)\right)$ \\
& $\times 0.66^{-1}$ \\
& $f_{\mathrm{T}}\left(T_{\mathrm{S}}\right)=0.68 \cdot \exp \left(0.1 \cdot\left(T_{\mathrm{S}}-7.1\right)\right)$ \\
& $\times 12.64^{-1}$ \\
\hline PnET $^{*}$ & \\
* Last terms in the equations are used to scale the original functions to the \\
CASA-CNP model as explained by Exbrayat et al. (2013a).
\end{tabular}

Mk3L-CABLE-CASA-CNP simulation. Once equilibrated offline, total $\mathrm{C}$ storage for each of the 27 equilibration runs was used to reinitialise the coupled climate model and a further spin-up was undertaken until soil $\mathrm{C}$ storage achieved steady state. Finally, historical transient runs including increasing atmospheric $\mathrm{CO}_{2}$, based on CMIP5 specifications, and driven by corresponding CSIRO Mk3.6 SSTs were performed for each of the 27 model versions for 1850-2005. By prescribing atmospheric $\mathrm{CO}_{2}$ we recognise that we limit the land-atmosphere coupling to energy and water exchanges between the land and the atmosphere. This is not a full coupling (e.g. Friedlingstein et al., 2006) where atmospheric carbon is also affected by terrestrial primary production and respiration fluxes. Further, we use a fixed land use map for each model version with dominant plant functional types set following the land cover data for 2005 from Hurtt et al. (2006). However, our experiments permit an assessment of how the choice of $f_{\mathrm{W}}, f_{\mathrm{T}}$ and nutrients affect terrestrial systems and $R_{\mathrm{h}}$ more simply than if we allowed for these feedbacks, or if we allowed ocean-atmosphere exchanges or land use change to affect atmospheric $\mathrm{CO}_{2}$. We note, of course, that these fluxes are included implicitly in the prescribed atmospheric $\mathrm{CO}_{2}$ data. Finally, by using the same radiative forcing in all simulations, we isolate the effect of the different $R_{\mathrm{h}}$ parameterisations on the terrestrial carbon cycle more simply than if variations in atmospheric $\mathrm{CO}_{2}$ occurred in our simulations. For simplicity, we could have driven CASA-CNP with prescribed historical weather observations but using a climate model provides the opportunity to perform 21 st century projections in future analyses.

\section{Results}

\subsection{Global land carbon balance}

Equilibrated total soil carbon is presented in Table 3 for each model version. Globally, for the same combination of $f_{\mathrm{T}}$ and $f_{\mathrm{W}}$, soil carbon in $\mathrm{CN}$ mode equilibrates at a level between 72 and $86 \%$ of the C-only mode, while differences
Table 3. Initial total soil carbon at equilibrium for each combination of $f_{\mathrm{W}}$ (rows) and $f_{\mathrm{T}}$ (columns) in C-only/CN/CNP modes. Values are given in $\mathrm{PgC}$ and rounded to the nearest unit.

\begin{tabular}{llll}
\hline \multicolumn{4}{l}{$f_{\mathrm{T}}$} \\
\hline$f_{\mathrm{W}}$ & CASA & K1995 & PnET \\
\hline CASA-CNP & $956 / 765 / 744$ & $1400 / 1211 / 1196$ & $3045 / 2591 / 2566$ \\
SOILN & $1371 / 1030 / 1003$ & $2096 / 1699 / 1678$ & $4283 / 3494 / 3447$ \\
TRIFFID & $1314 / 940 / 904$ & $1804 / 1441 / 1415$ & $3730 / 2943 / 2894$ \\
\hline
\end{tabular}

between $\mathrm{CN}$ and $\mathrm{CNP}$ are negligible. However, regardless of the biogeochemical mode adopted, differences in $f_{\mathrm{T}}$ and $f_{\mathrm{W}}$ introduce a difference of 4.5 times between the version that simulates the largest soil carbon pool (SOILN $f_{\mathrm{W}}$ with PnET $f_{\mathrm{T}}$ ) and the version that simulates the smallest (the original CASA-CNP version) in response to similar NPP during spin-up: $48.0 \pm 0.1 \mathrm{Pg} \mathrm{Ca}^{-1}, 46.2 \pm 0.7 \mathrm{Pg} \mathrm{Ca}^{-1}$ and $45.1 \pm 0.7 \mathrm{Pg} \mathrm{Ca}^{-1}$ in C-only, $\mathrm{CN}$ and CNP mode, respectively ( \pm 1 standard deviation).

The cumulative global net ecosystem accumulation (NEA) of terrestrial carbon since 1850 is shown in Fig. 2 (a positive accumulation corresponds to a net terrestrial sink). Each panel in Fig. 2 shows results for all nine combinations of $f_{\mathrm{W}}$ and $f_{\mathrm{T}}$ for a given C-only (Fig. 2a), CN (Fig. 2b) or CNP (Fig. 2c) mode using thin lines, and their style represents which $f_{\mathrm{T}}$ was used in each model as indicated. The shaded area represents the total simulated range for a given nutrient limitation mode. All simulations show a net accumulation of carbon over the 20th century at the global scale as NPP increases on average due to a combination of $\mathrm{CO}_{2}$ fertilisation and warmer temperatures driven by the observed $\mathrm{CO}_{2}$ increases. However, there are major differences between the results from the C-only, $\mathrm{CN}$ and $\mathrm{CNP}$ modes and between the various moisture and temperature functions.

For the C-only mode, the range in the simulated NEA introduced by different $f_{\mathrm{W}}$ and $f_{\mathrm{T}}$ is very large, ranging from 207 to $438 \mathrm{Pg} \mathrm{C}$ (Fig. 2a). To illustrate the magnitude of the terrestrial sink, this represents $\sim 43$ to $\sim 92 \%$ of the $\sim 475 \mathrm{Pg} \mathrm{C}$ of accumulated emissions from fossil-fuel and land-use change represented in each panel of Fig. 2 from data by the Carbon Dioxide Information Analysis Center (CDIAC - Houghton, 2008; Boden et al., 2010). Adding N limitation reduces the terrestrial sink to between 61 and $175 \mathrm{PgC}$ for the 20th century, or 13 and $37 \%$ of anthropogenic fossil-fuel emissions. This is more in accordance with Global Carbon Project estimates of uptake that vary around $30 \%$ (Le Quéré et al., 2009). The range of NEA simulated in the CN mode, resulting from the choice of $f_{\mathrm{W}}$ and $f_{\mathrm{T}}$, also decreases by about a factor of two relative to the C-only mode. The results from the CNP mode demonstrate a further reduction in both the magnitude and variability in NEA to $41-134 \mathrm{Pg} \mathrm{C}$ or $\sim 9$ to $\sim 28 \%$ of anthropogenic emissions. Note that while the uncertainty ranges of $\mathrm{CN}$ and $\mathrm{CNP}$ modes overlap, the 

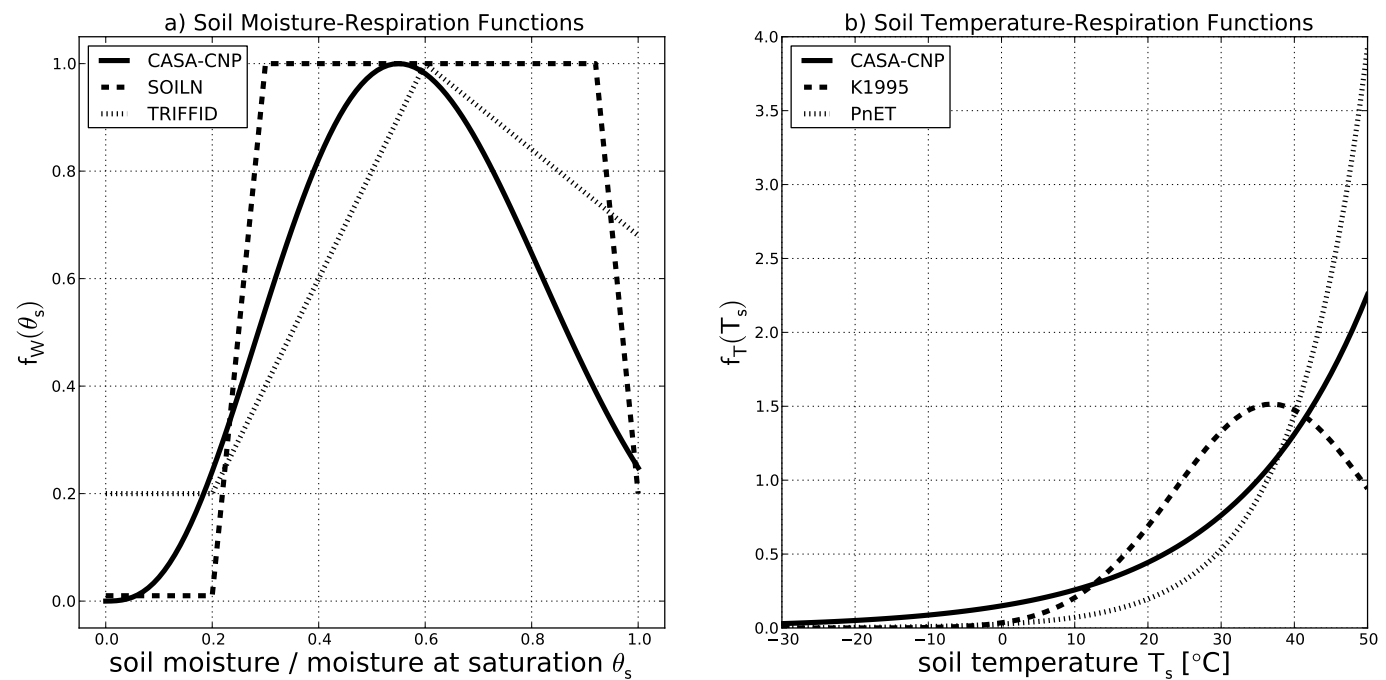

Fig. 1. Various $f_{\mathrm{T}}$ and $f_{\mathrm{W}}$ implemented in the CASA-CNP model code.

lowest member of the C-mode family (Fig. 2a) accumulates $\sim 40 \mathrm{PgC}$ more than the highest member of the $\mathrm{CN}$ and CNP simulations (Fig. 2b, c). It is interesting to note that in each mode there is a great interaction between $f_{\mathrm{T}}$ and $f_{\mathrm{W}}$ as shown by the position of model versions using the same temperature function alternatively at the higher or lower end of the simulated range.

We compare these simulations with previous estimates of global terrestrial NEA. Figure 3 compares our simulation results with estimates using the time period overlapping our simulations from the Global Carbon Project (19592005; Canadell et al., 2007, data accessible at http://www. globalcarbonproject.org/carbontrends) and an intercomparison study of dynamic global vegetation models (1958-2002; Sitch et al., 2008). Every simulation in the C-only mode, for all combinations of $f_{\mathrm{T}}$ and $f_{\mathrm{W}}$, overestimates NEA as compared to previous studies. Generally, results for the mean terrestrial uptake from the $\mathrm{CN}$ and $\mathrm{CNP}$ models are more consistent with the estimates by Canadell et al. (2007) and Sitch et al. (2008). CN mode is actually the most similar to previous estimates with almost all combinations of $f_{\mathrm{T}}$ and $f_{\mathrm{W}}$ within the $\sim 0.75 \mathrm{Pg} \mathrm{Ca}^{-1}$ uncertainty range provided by Sitch et al. (2008) and matching the estimate of Canadell et al. (2007). Over the same period all CNP simulations are below the range suggested by Sitch et al. (2008). The lower panel of Fig. 3 shows the variability of the land sink as illustrated by the standard deviation of annual NEA. C-only mode simulates excessive variability compared to Canadell et al. (2007). Both the $\mathrm{CN}$ and CNP modes are closer to Canadell et al. (2007) though slightly high.

Although $\mathrm{N}$ and $\mathrm{P}$ limitations reduce the absolute range in NEA, differences in $f_{\mathrm{W}}$ and $f_{\mathrm{T}}$ lead some model versions with equivalent $\mathrm{N}$ and $\mathrm{P}$ limitations to simulate twice as much NEA as other versions. This is true of C-only, CN and CNP modes (Figs. 2 and 3). To illustrate this, we analyse the annual NEA normalised by the annual NPP. We chose NPP because while it is affected by NP limitations, it is very similar between versions within the same nutrient mode and hence appears sensitive to the choice of $f_{\mathrm{T}}$ and $f_{\mathrm{W}}$ (Figs. S1, S2 and S3 in Supplement). The lower panel in Fig. 3 indicates that, by reducing all $\mathrm{C}$ fluxes and turnover processes, NP limitations reduce the inter-annual variability of land-atmosphere carbon fluxes. As a result, CN and CNP modes (Fig. 4b, c) do not exhibit the post-1960 step change in NEA that corresponds to a greater carbon sink in the C-only model (Fig. 4a) in response to the sudden increase in the growth rate of atmospheric $\mathrm{CO}_{2}$ concentrations (Supplement Fig. S4). As a result, uncertainty ranges in Fig. $4 \mathrm{~b}$ and $\mathrm{c}$ show that the ensembles of NP-limited simulations more often contain both net sources and net sinks during a same year as they overlap the dotted line that represents zero NEA. However, differences in $f_{\mathrm{T}}$ and $f_{\mathrm{W}}$ still introduce a two-fold uncertainty in cumulative historical NEA as shown in Fig. 2 even though the ensemble spread appears small relative to the effect of introducing NP limitations. To compare the spread generated by the different $f_{\mathrm{W}}$ and $f_{\mathrm{T}}$ relative to variability in NEA/NPP, we calculate a measure analogous to a signal-to-noise ratio for each C-only, CN and CNP mode. We define the "signal" as the temporal variability in NEA/NPP, calculated as the standard deviation of the annual mean NEA/NPP (the annual mean is represented by the black line in Fig. 4). The "noise" is calculated as the intra-annual variability between combinations of $f_{\mathrm{W}}$ and $f_{\mathrm{T}}$. It corresponds to the standard deviation of the distance between all models and the mean NEA/NPP for all years (full ranges with maximum distances are in grey in Fig. 4). This signal-to-noise ratio decreases from 3.8 in C-only mode to 1.7 and 1.4 in $\mathrm{CN}$ and CNP modes, respectively. This indicates that the uncertainty due to $f_{\mathrm{W}}$ and $f_{\mathrm{T}}$ 


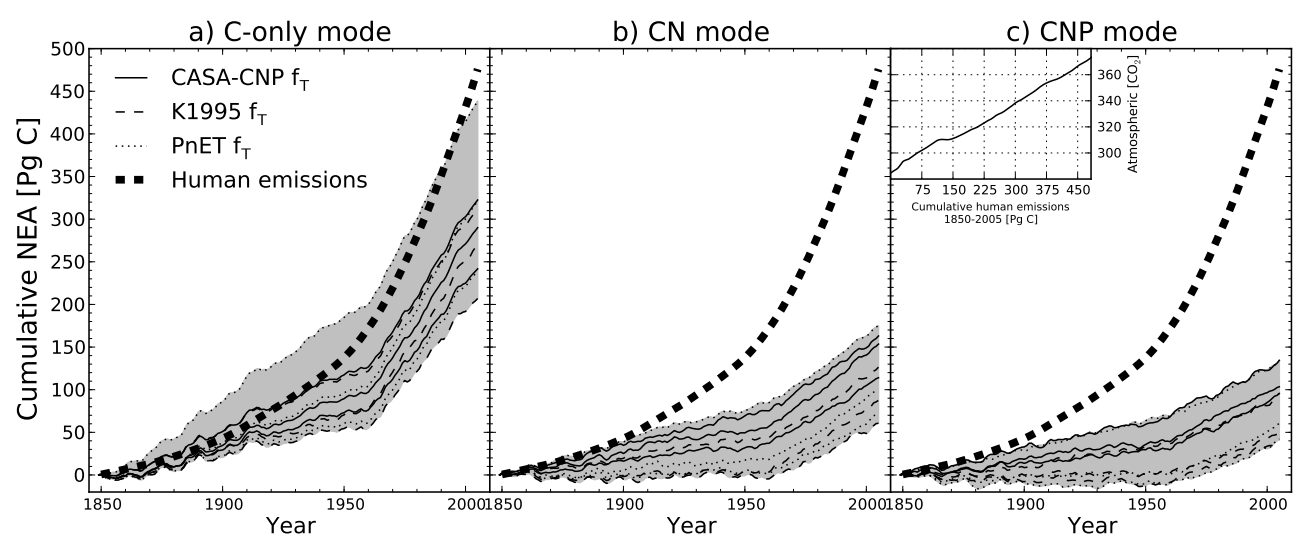

Fig. 2. Global cumulative human carbon emissions and modelled net ecosystem accumulation (NEA) throughout the historical period using CASA-CNP in C, CN and CNP modes. In each panel, the shaded area represents the range of NEA simulated by the nine combinations of $f_{\mathrm{W}}$ and $f_{\mathrm{T}}$ in the indicated nutrient mode, while thin lines represent individual simulations identified by $f_{\mathrm{T}}$. The insert in the right panel shows the relationship between cumulative human emissions and atmospheric $\mathrm{CO}_{2}$ (in ppmv) over the same period as the model is driven by this latter.

relative to the variability in NEA increases when NP limitations are added. From Fig. 4, it is clear that this results from the lack of signal in response to post-1960 increase in atmospheric $\mathrm{CO}_{2}$.

We next investigate the regional implications of the choice of $f_{\mathrm{W}}$ and $f_{\mathrm{T}}$ to explain the four-fold range in soil carbon and two-fold range in NEA simulated between simulations with the same nutrient limitation.

\subsection{Regional variations}

We are aware that data by Canadell et al. (2007) and Sitch et al. (2008) are based on model simulations that do not integrate NP limitation. However, they integrate processes that were not represented in our modelling system for the purpose of simplifying the understanding of our results. Further, the good agreement of these previous studies makes us more confident on the reliability of $\mathrm{CN}$ and CNP simulations in terms of response to the historical increase in atmospheric $\mathrm{CO}_{2}$. Therefore, we will use $\mathrm{CN}$ simulations as reference in the remainder of the manuscript, as they were the most similar to these independent estimates of global NEA for 19592005 (Sect. 3.1).

The soil $\mathrm{C}$ density at equilibration for all $\mathrm{CN}$ simulations is shown in Fig. 4. Each panel in Fig. 5 represents a combination of a $f_{\mathrm{W}}$ (rows) with a $f_{\mathrm{T}}$ (columns). Large differences are observed in pool sizes as a function of $f_{\mathrm{W}}$ and $f_{\mathrm{T}}$ (similar patterns exist in C-only and CNP simulations). For example, the K1995 and PnET $f_{\mathrm{T}}$ both equilibrate at much higher carbon density than CASA-CNP functions in the mid- to high latitudes in the Northern Hemisphere. PnET also has a higher soil C density in warmer regions. Differences implied by $f_{\mathrm{W}}$ are more localised and do not seem to depend on a latitudinal gradient. SOILN equilibrates at a higher level of soil $\mathrm{C}$ in dry regions of south-west Australia, southern Africa and the
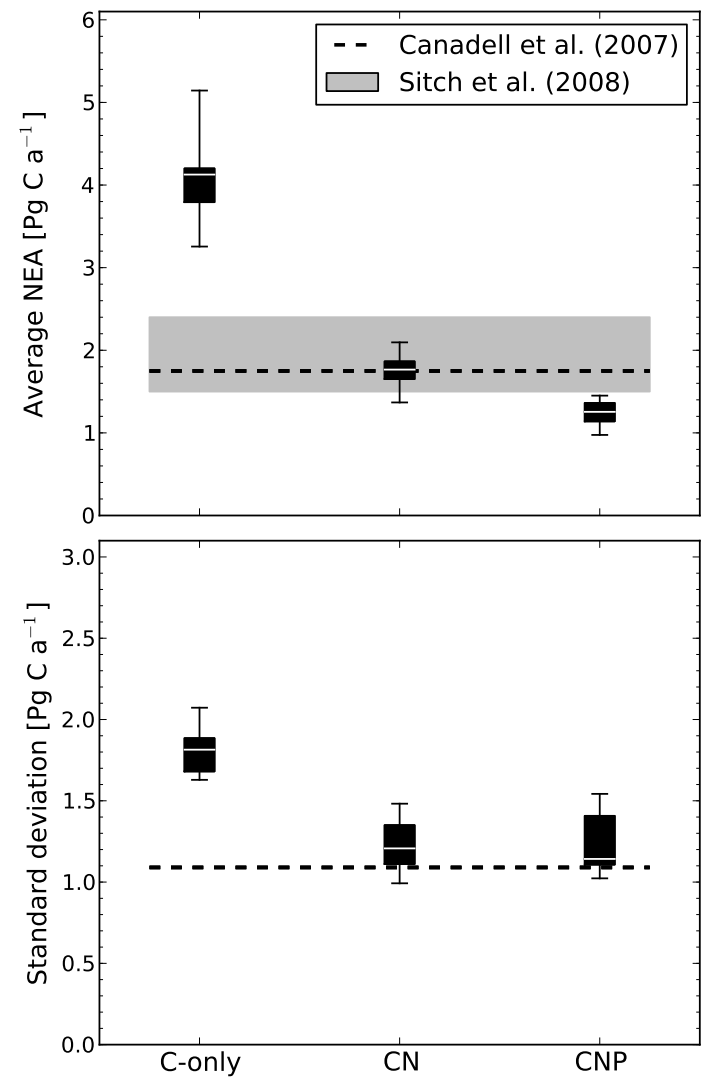

Fig. 3. Comparison of simulated NEA with previous studies. Box plots indicate the range in the mean NEA (upper panel) and standard deviation (lower panel) simulated by all combinations of $f_{\mathrm{W}}$ and $f_{\mathrm{T}}$ in a specific nutrient limitation mode as indicated. Markers represent quartiles. Note data from Canadell et al. (2007) indicate range over the period 1959-2005 and data from Sitch et al. (2008) indicate range over the period 1958-2002. 


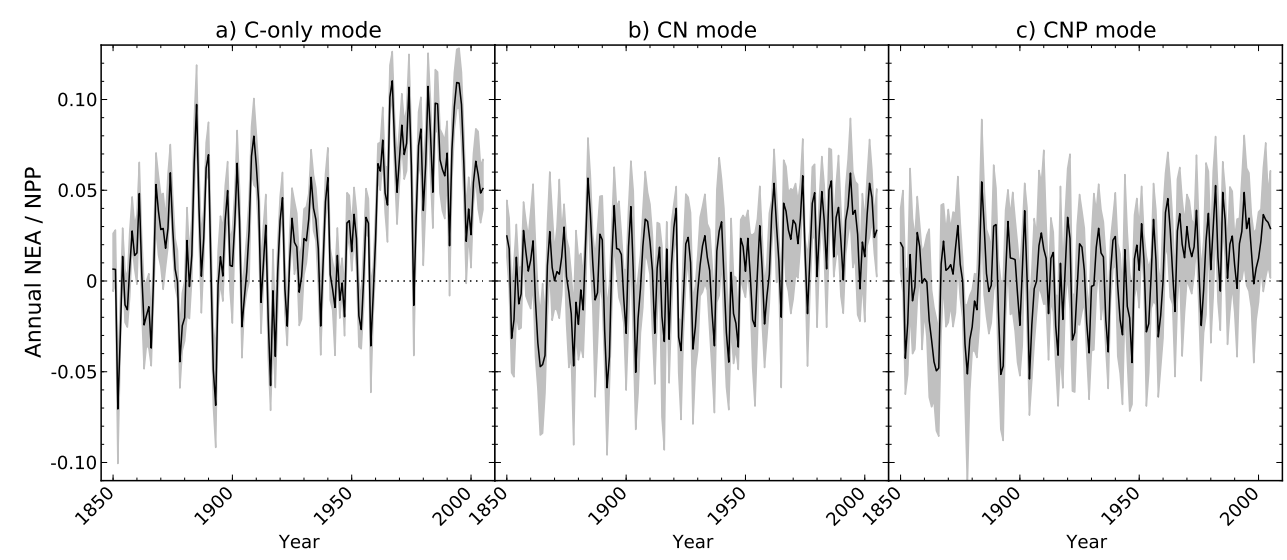

Fig. 4. Time series of net ecosystem accumulation (NEA) normalised by net primary productivity (NPP) for all combinations of a $f_{\mathrm{W}}$ and a $f_{\mathrm{T}}$ in a specific nutrient limitation mode as indicated. Negative values indicate a net sink. The black line represents the annual mean, while the shading corresponds to the range of the individual model versions within each mode.

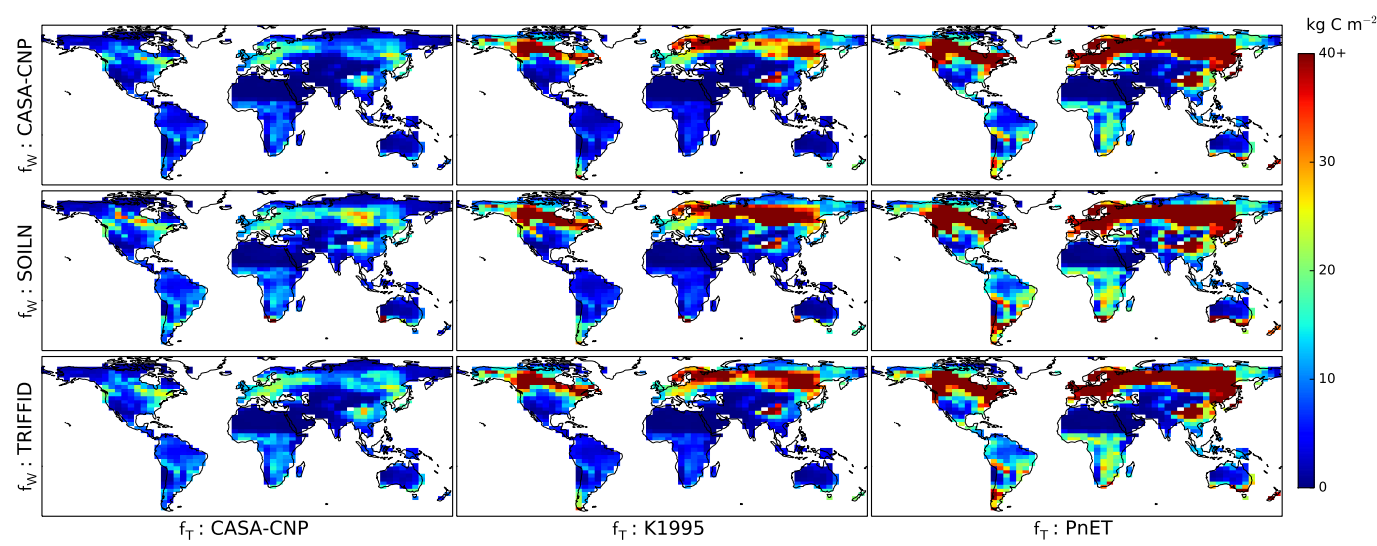

Fig. 5. Soil C density at equilibration in 1850 in $\mathrm{CN}$ simulations.

western edge of South America, while the two other $f_{\mathrm{W}}$ provide relatively similar results when used with the same $f_{\mathrm{T}}$.

Besides leading model versions to equilibrate at various levels of soil carbon both locally and globally, the different functions do not have the same sensitivity to a similar change in the soil temperature or moisture as shown by their respective shapes (Fig. 1). Figure 6 shows the change in the average value of the environmental scalar $f_{\mathrm{W}}\left(\theta_{\mathrm{S}}\right) \times f_{\mathrm{T}}\left(T_{\mathrm{s}}\right)$ between the 10 first and 10 last years of the $\mathrm{CN}$ simulations. There are large variations between the different model versions depending on both $f_{\mathrm{W}}$ and $f_{\mathrm{T}}$. First, the decay rate (i.e. $R_{\mathrm{h}}$ per unit of $\mathrm{C}_{\mathrm{S}}$ ) does not increase everywhere and there are significant decreases in dry regions (e.g. Arabian Peninsula, western Sahara and western Australia) with the SOILN $f_{\mathrm{W}}$ used with the K1995 or PnET $f_{\mathrm{T}}$ as it is the most constraining function in dry conditions (Fig. 1). All model versions using the K1995 $f_{\mathrm{T}}$ have the highest relative increase in decay rate in northern Eurasia, while the other $f_{\mathrm{T}}$ do not imply an increase of more than $20 \%$ in $R_{\mathrm{h}}$ except when used with SOILN.

Differences in the regional response of $f_{\mathrm{T}}$ and $f_{\mathrm{W}}$ are likely to generate regional differences in the land carbon balance. Therefore, we now investigate spatial variations in NEA to understand the roughly two-fold difference in global NEA simulated by all model versions in each nutrient mode (Fig. 2). Figure 7 shows NEA between the periods of 19962005 and $1850-1859$ for each CN simulation. As it is significantly correlated $(p<0.001)$ with changes in soil carbon (Fig. S5), we can link NEA to how soil conditions affect the response of $R_{\mathrm{h}}$ depending on the choice of $f_{\mathrm{W}}$ and $f_{\mathrm{T}}$. Although regional differences appear depending on the choice of a $f_{\mathrm{W}}$ when keeping the same $f_{\mathrm{T}}$, most of the uncertainty in NEA is related to the choice of a $f_{\mathrm{T}}$. For example, most of the continents show an increase in land carbon between 1850 and 2005 using the CASA-CNP $f_{\mathrm{T}}$ (leftmost column), a result that is weakly sensitive to the choice of $f_{\mathrm{W}}$. Meanwhile, if the K1995 and especially PnET $f_{\mathrm{T}}$ is used (rightmost column), 


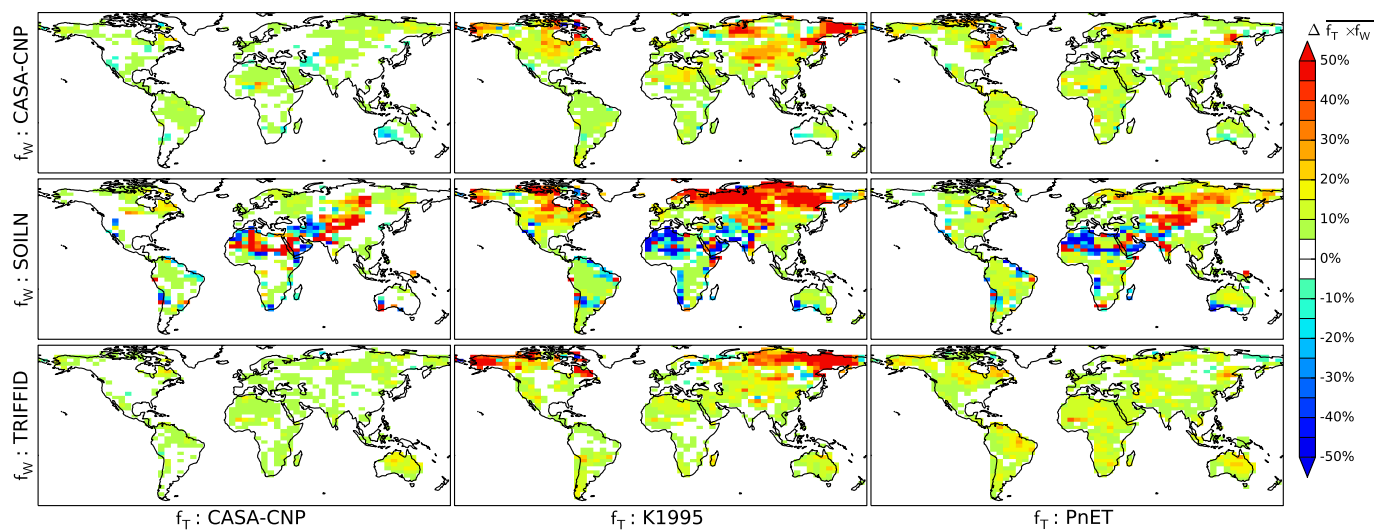

Fig. 6. Change in the average $f_{\mathrm{W}} \times f_{\mathrm{T}}$ product between the periods $1850-1859$ and $1995-2005$ relative to its initial value in CN simulations (in \%). Positive values mean that the product is greater at the end of the historical simulations than at the beginning.

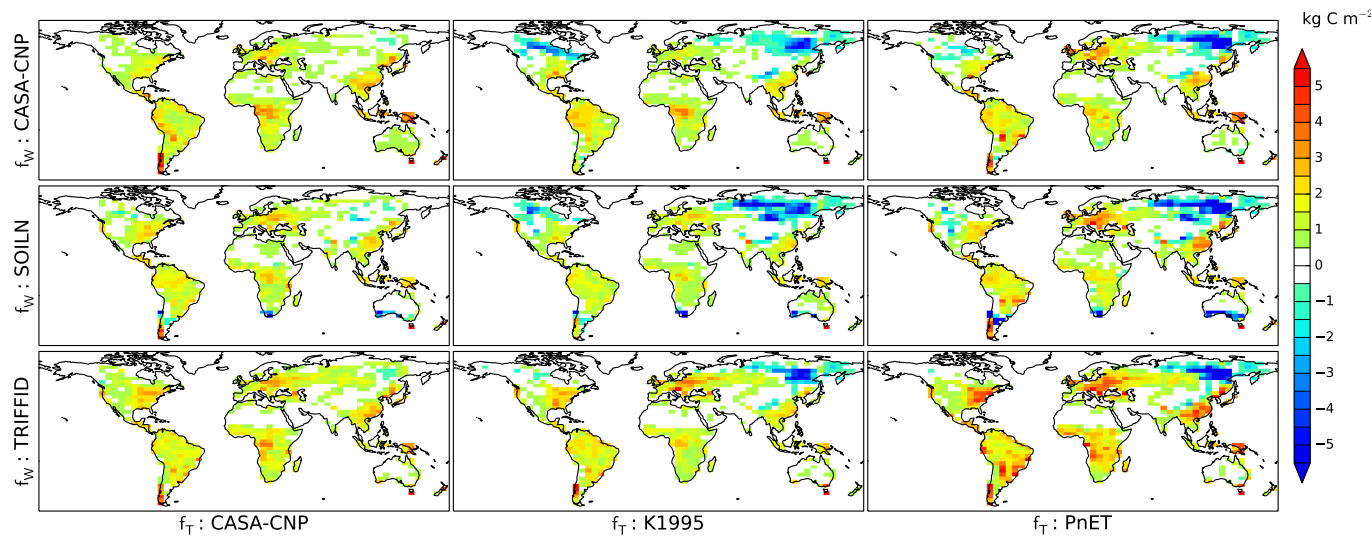

Fig. 7. Cumulative NEA during historical simulations as represented by the difference in the average land carbon between the periods 1996-2005 and 1850-1859 in CN simulations. Each sub-panel corresponds to a single combination of response functions as indicated.

a large region of negative NEA (i.e. a net source of $\mathrm{CO}_{2}$ ) is simulated in the northern latitudes of eastern Eurasia. This negative NEA occurs irrespective of the choice of $f_{\mathrm{W}}$. The K1995 and PnET $f_{\mathrm{T}}$ also simulate a negative NEA over high latitudes of North America which we attribute to soil warming that triggers higher $R_{\mathrm{h}}$ that offset any increases in NPP, but only if the CASA-CNP and SOILN $f_{\mathrm{W}}$ are used. The moisture functions nevertheless lead to large regional differences, especially over central Europe. Figure 7 shows a gradual increase in NEA from the CASA-CNP $f_{\mathrm{W}}$, through the SOILN $f_{\mathrm{W}}$ to the TRIFFID $f_{\mathrm{W}}$. This additional sink is most apparent when the PnET $f_{\mathrm{T}}$ is used as TRIFFID accumulates soil carbon in places where the CASA-CNP and SOILN $f_{\mathrm{W}}$ lose carbon (e.g. Americas). Although we see regional differences in NEA depending on $f_{\mathrm{T}}$ and $f_{\mathrm{W}}$, we note that places where the environmental scalar and hence the decay rate (or $R_{\mathrm{h}}$ per unit of $\mathrm{C}_{\mathrm{s}}$ ) increased the most (red colours on Fig. 6) are not where most soil C is lost (blue colours on Fig. 7 and S5), except perhaps when using the SOILN $f_{\mathrm{W}}$ with the K1995 $f_{\mathrm{T}}$. Based on linear regressions (not shown) the change in environmental scalar values does not explain more than $12 \%$ of the variability in the change of soil carbon and NEA.

The spatial influence of $\mathrm{N}$ limitation on the C-only simulations can be examined by comparing total NEA between $\mathrm{C}$-only and $\mathrm{CN}$ simulations (Fig. 8) as well as differences in soil carbon changes (Fig. S6). The most obvious differences are in the mid- and high latitudes of the Northern Hemisphere (in red on Fig. 8 and S2). There, C-only simulations store up to $5 \mathrm{~kg} \mathrm{C} \mathrm{m}^{-2}$ (Fig. 8) more than $\mathrm{CN}$ simulations as a result of no nutrient limitation applied to NPP (also Fig. 2). Differences of the same magnitude are observed in soil carbon changes (Fig. S6). In large regions across the Northern Hemisphere, the difference is large enough to change the sign of NEA over the historical period from net sources in $\mathrm{CN}$ simulations to net sinks in C-only simulations (stippling on Fig. 6), especially with the K1995 $f_{\mathrm{T}}$. Elsewhere, differences in NEA and soil carbon change between the C-only and CN simulations are commonly small $\left(<1 \mathrm{~kg} \mathrm{C} \mathrm{m}^{-2}\right)$. Local responses are, however, dependent on the choice of both $f_{\mathrm{W}}$ 


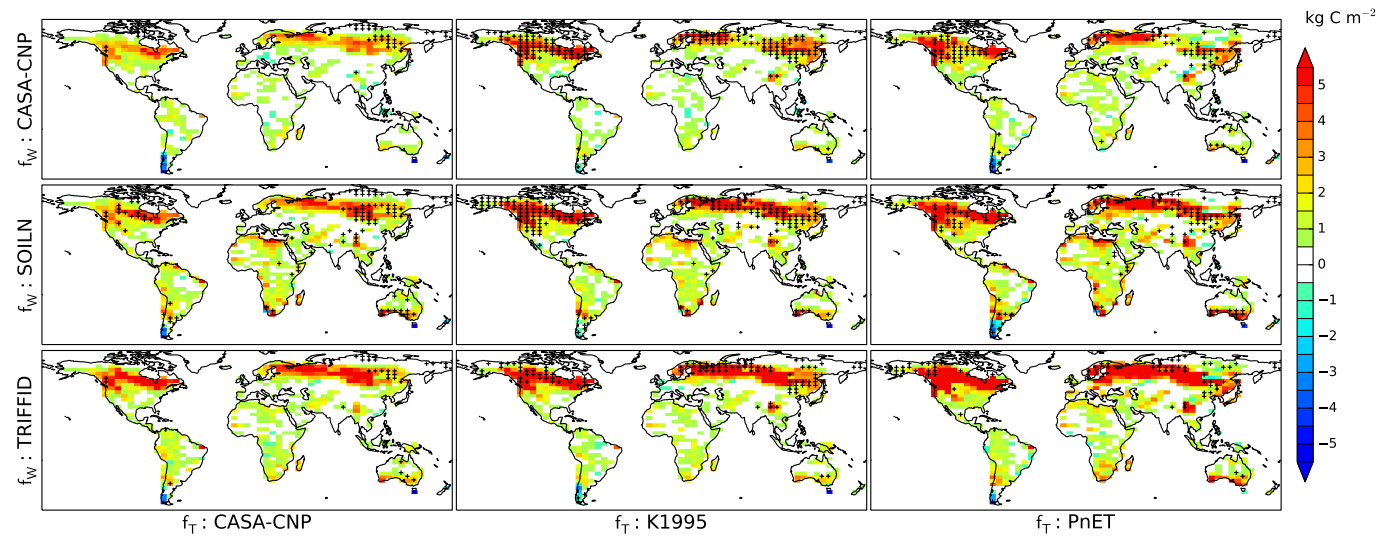

Fig. 8. Difference in cumulative NEA between C-only and $\mathrm{CN}$ historical simulations for the same combination of $f_{\mathrm{W}}$ and $f_{\mathrm{T}}$. Stippling represent areas where the sign of cumulative NEA is different between $\mathrm{C}$-only and $\mathrm{CN}$ simulations.

and $f_{\mathrm{T}}$. For example, for each $f_{\mathrm{T}}$, there is a relatively large variation in soil carbon accumulation between the CASACNP $f_{\mathrm{W}}$ and the TRIFFID $f_{\mathrm{W}}$ (Supplement Fig. S6).

In comparison with the effect of including $\mathrm{N}$ limitation, the consequences of including P limitation are minor (Fig. S7 and S8). In terms of NEA, there is a further reduction in comparison to the $\mathrm{CN}$-limited simulations but the magnitude of the reduction is at most $\sim 1 \mathrm{~kg} \mathrm{C} \mathrm{m}^{-2}$ and only a few places see a change in the sign of NEA between CNP and CN simulations. However, we note that some regions have higher NEA in CNP simulations than in CN simulations despite the additional P limitation on NPP. Similarly, the effect on soil carbon from the addition of $\mathrm{P}$ limitation is generally small in comparison to the addition of $\mathrm{N}$ limitation and broad differences between the temperature and moisture functions are even smaller than for NEA (Supplement Fig. S8). Overall tiny regional differences between $\mathrm{CN}$ and CNP simulations sum up to a similar global signal.

\section{Discussion}

\subsection{Equilibration of soil carbon}

Using different formulations of $f_{\mathrm{T}}$ and $f_{\mathrm{W}}$ leads to significant differences in the outcome of the spin-up procedure (Fig. 5). In our simulations, all model versions were brought to equilibrium until $\mathrm{C}$ pools achieved a steady state. This is a standard procedure (e.g. Wang et al., 2010; Xia et al., 2012) that would most likely have been used in all CMIP5 simulations that incorporated carbon. Spinning up a model means integrating the model with steady boundary conditions until the trend in carbon pool is negligible or $R_{\mathrm{h}} \approx \mathrm{NPP}$. According to Eq. (1), in ESMs, the amount of decomposition, and therefore $R_{\mathrm{h}}$, is controlled by a time-invariant reference $k$ parameter, the $f_{\mathrm{W}}\left(\theta_{\mathrm{S}}\right) \times f_{\mathrm{T}}\left(T_{\mathrm{S}}\right)$ product and the amount $C_{\mathrm{S}}$ of carbon available in soil for decomposition. Model equili- bration consists of achieving the carbon pool size needed to simulate $R_{\mathrm{h}}$ at a level that compensates for NPP, while integrating the model under steady boundary conditions. Given that NPP is similar between simulations within the same nutrient mode (Supplement Figs. S1, S2 and S3), it is only our modifications to $f_{\mathrm{W}}$ and $f_{\mathrm{T}}$ that have led to total soil $\mathrm{C}$ in our $\mathrm{CN}$ model to range from $765 \mathrm{Pg} \mathrm{C}$ to $3495 \mathrm{Pg} \mathrm{C}$. As shown in Fig. 5, differences in total soil carbon at equilibrium are due to large regional differences, especially at high latitudes. This can be explained by the relative position of these functions for cold temperatures (Fig. 1): the CASACNP $f_{\mathrm{T}}$ is systematically above the two other $f_{\mathrm{T}}$ for soil temperatures below $10^{\circ} \mathrm{C}$. It therefore requires less substrate to simulate $R_{\mathrm{h}}$ at a level that compensates for the same NPP than K1995 and PnET. Conversely, PnET causes the model to equilibrate at a higher soil $\mathrm{C}$ density in warmer regions as it is well below the two other functions for soil temperature corresponding to Africa and South America. As there are dry and wet regions at any latitude, differences implied by $f_{\mathrm{W}}$ are more localised. However, the same relationship between the relative positions of the curves can be seen. The most noticeable feature is that SOILN, a very limiting $f_{\mathrm{W}}$ in dry conditions, equilibrates at a higher level than the two other $f_{\mathrm{W}}$ in south-west Australia, southern Africa and the western edge of South America, where it requires more substrate to achieve the same $R_{\mathrm{h}}$ to compensate NPP.

In Fig. 5 we adopted a colour scale similar to Fig. 3 of Todd-Brown et al. (2013) to present soil C in different CMIP5 ESMs. The regional differences implied by the different $f_{\mathrm{W}}$ and $f_{\mathrm{T}}$ map particularly well onto the diversity shown by the CMIP5 models and total soil carbon approximates the six-fold range found in CMIP5 models (Todd-Brown et al., 2013), although these include models well outside of the $95 \%$ confidence interval of $890-1660 \mathrm{PgC}$ in current soil (Todd-Brown et al., 2013). For example, five of our CN simulations do not fall within the 890 to $1660 \mathrm{Pg} \mathrm{C} 95 \%$ confidence interval of present soil carbon reported by Todd-Brown 
et al. (2013). Dismissing them leads our projected range of cumulative historical NEA to shrink by about a third from 61-175 Pg C to 86-161 Pg C. We do not explore this more in detail here but we suspect that these similarities between our simulations and CMIP5 results nevertheless strongly indicate that the formulation of the time and space invariant $f_{\mathrm{W}}$ and $f_{\mathrm{T}}$ is a key source of uncertainty in the equilibrium of these models. We note, however, that CMIP5 models also vary three-fold in their NPP, with much lower values in N-limited models, as well as in the number of pools they employ. They are also likely to use different values of $k$ as shown by ToddBrown et al. (2013) with their reduced complexity models. Equation (1) highlights that in the first-order parameterisation of microbial decomposition, substrate availability $\mathrm{C}_{\mathrm{s}}$ is also a regulating factor. Therefore, we explore hereafter the influence of initial conditions on the soil carbon response, especially since the change in the environmental scalar through time cannot explain NEA.

\subsection{Response to transient conditions}

Despite variations in total soil carbon content, all model versions simulate a positive NEA linked with increasing $\mathrm{CO}_{2}$ emissions (Fig. 2) over the 20th century irrespective of nutrient limitation mode or the choice of $f_{\mathrm{W}}$ or $f_{\mathrm{T}}$. This means that each model version simulates the terrestrial biosphere as a net carbon sink associated with the fertilisation effect of increasing atmospheric $\mathrm{CO}_{2}$ and temperature over the 20th century. This has been described previously in CASA-CNP and other coupled models whether or not they included NP interactions with C (Cox et al., 2000; Friedlingstein et al., 2006; Sitch et al., 2008; Zhang et al., 2011). The similarity of NPP for simulations with the same nutrient limitation indicate that there is only poor interaction between response functions and mineralisation of nutrients for these historical simulations, although this may be a non-negligible process for NPP in a warmer future (Zaehle et al., 2010a).

However, comparing our range of results due to different formulations of $f_{\mathrm{W}}$ and $f_{\mathrm{T}}$ across the three nutrient modes with estimates of NEA from Canadell et al. (2007) and Sitch et al. (2008) suggests that the C-only mode simulates an excessively high terrestrial uptake. In general, the $\mathrm{CN}$ mode appears most consistent with other estimates. Earlier studies, each using a single $f_{\mathrm{W}}$ or $f_{\mathrm{T}}$, predicted a reduction in the $\mathrm{CO}_{2}$ fertilisation effect by up to $72 \%$ when considering $\mathrm{N}$ limitation (Thornton et al., 2007; Sokolov et al., 2008; Jain et al., 2009; Zaehle et al., 2010b; Bonan and Levis, 2010; Zhang et al., 2011), and our average reduction of $64 \%$ in global NEA (Fig. 2) due to $\mathrm{N}$ limitations is consistent with these previous estimates. Our results suggest that reductions in $\mathrm{CO}_{2}$ fertilisation simulated by CASA-CNP in response to $\mathrm{N}$ and $\mathrm{P}$ limitations (Zhang et al., 2011) are robust to the choice of $f_{\mathrm{T}}$ or $f_{\mathrm{W}}$.

Of course, it would be straightforward to calibrate the model in C-only mode to reduce the overestimation of NEA, but then the $\mathrm{CN}$ and CNP modes would grossly underestimate observations. Further, parameter values optimised to reproduce observed data would likely compensate for the lack of representation of key biogeochemical processes ( $\mathrm{N}$ and $\mathrm{P})$, introducing a high risk of obtaining acceptable simulations for the wrong reasons. It has been demonstrated that over-fitted parameters that provided acceptable calibration results were not able to capture the response of a system to changes if some processes were missing in the model structure (e.g. Exbrayat et al., 2013b). Since the availability of $\mathrm{N}$ and $\mathrm{P}$ has a key influence on NPP that supplies substrate for decomposition and affects NEA (Vitousek and Howarth, 1991; Luo et al., 2004; Vitousek et al., 2010; Goll et al., 2012), results from $\mathrm{CN}$ and CNP are likely more robust than C-only. Rather than calibrating a C-only version, adding $\mathrm{N}$ and $\mathrm{P}$ to more correctly reflect the response of the biogeochemical system to increase in atmospheric $\mathrm{CO}_{2}$ and temperature is preferable.

The two-fold range in NEA introduced by $f_{\mathrm{W}}$ and $f_{\mathrm{T}}$ remains under all nutrient limitation modes, and this can be attributed to large regional differences in the Northern Hemisphere (Fig. 7). There, NEA changes from a carbon sink to a carbon source in response to very similar NPP within the same nutrient mode. Further, differences in NEA and soil carbon change cannot be explained by the change imposed on the environmental scalar (Fig. 6 and Sect. 3.2). Therefore, only the amount of available substrate can explain these differences in $R_{\mathrm{h}}$. Figure 9 presents the change in soil C as a function of initial conditions (i.e. in 1850 after spin-up) in all simulations. Grid boxes with low initial values can gain or lose $\mathrm{C}$ for all combinations of a $f_{\mathrm{W}}$ with a $f_{\mathrm{T}}$. The Conly simulations accumulate soil $\mathrm{C}$ almost everywhere because the lack of nutrient limitation allows for a stronger response of NPP which dominates the response and offsets $R_{\mathrm{h}}$. In contrast, in the nutrient-limited $\mathrm{CN}$ and CNP, soil carbon losses are observed where substrate availability is initially high. This is particularly true for K1995 and PnET $f_{\mathrm{T}}$ (Fig. 9, central and rightmost columns). In these simulations where NPP is limited by nutrient availability, even a small relative increase in the environmental scalar $f_{\mathrm{W}}\left(\theta_{\mathrm{S}}\right) \times f_{\mathrm{T}}\left(T_{\mathrm{S}}\right)$ applied to initially large pools enhances $R_{\mathrm{h}}$ enough to transform some local carbon sinks into sources. Further, CN simulations generally equilibrate at higher soil carbon content than CNP simulations (Table 3). Hence, in regions where large initial soil carbon pools trigger losses during simulations, $\mathrm{CN}$ runs lose a bit more carbon than the corresponding CNP runs. Nevertheless, it is worth noting that $\mathrm{CN}$ and CNP simulations are quite comparable under historical forcing despite the added complexity of $\mathrm{P}$ limitation. This characteristic may still involve heterogeneous responses of $\mathrm{CN}$ and CNP modes to future climate change, something that remains to be explored beyond the work presented here (see e.g. Zhang et al., 2011; Goll et al., 2012).

We see here an analogy with the model-specific nature of soil moisture described by Koster et al. (2009). That is, the 

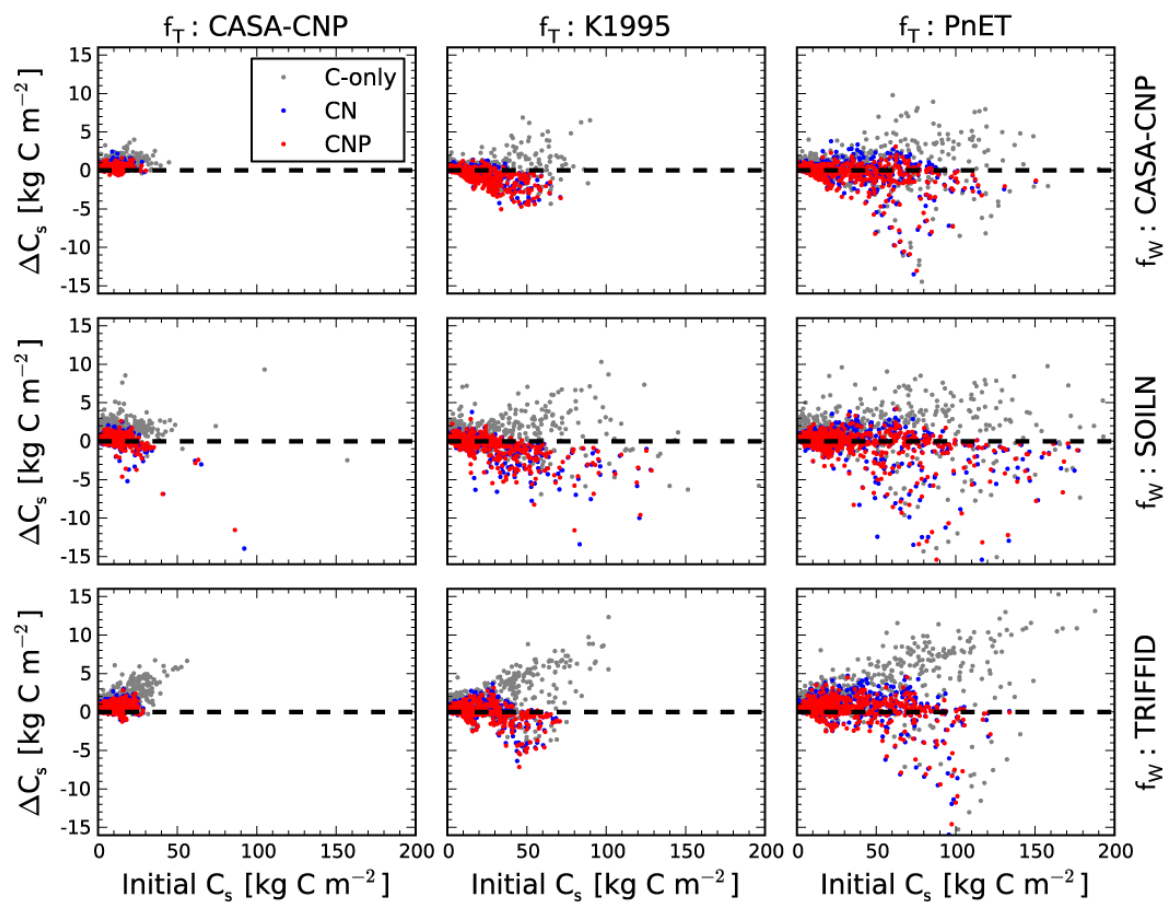

Fig. 9. Change in soil carbon $C_{\mathrm{s}}$ as a function of initial value for all grid boxes for all simulations in C-only, CN and CNP modes as indicated.

amount of soil $\mathrm{C}$ as simulated in ESMs is not something that can be directly compared with a quantity that might be measured in the field. Rather, soil $\mathrm{C}$ in each model is the value required by the model to reach steady state, and through which variations trigger an acceptable response of land-atmosphere exchanges to historical changes. Since observations are not available to constrain the model in the future, a large uncertainty arises that can be exemplified by the lack of consensus between model projections in a previous inter-comparison project despite a rather good agreement for historical simulations (Friedlingstein et al., 2006). This adds to recently stated concerns that the current parameterisation of decomposition is not representative of our understanding of this process (Allison et al., 2010; Schmidt et al., 2011; Todd-Brown et al., 2012). Our results point to a critical need to refine the initialisation of ESMs by spin-up as it controls the sign of change in soil $\mathrm{C}$ and NEA, and hence the carbon-climate feedback from the land on the atmosphere. This is especially true when the dominant $\mathrm{CO}_{2}$-fertilisation effect is reduced by more realistic nutrient limitation. Although we do not explore this here, we suggest that gridded data sets of current soil carbon content such as those presented by Tarnocai et al. (2009) for high latitudes, or Todd-Brown et al. (2013) globally, could possibly be used as guidelines to constrain soil carbon. Since methods now exist that greatly speed up the spin-up procedure (Xia et al., 2012) - the most expensive part of such simulations - trial and error procedures are feasible.

\section{Conclusions}

We have used 27 combinations of $f_{\mathrm{T}}, f_{\mathrm{W}}$ and nutrient limitations in an ESM to explore how the land carbon balance responds to changing atmospheric $\mathrm{CO}_{2}$ over the period 1850 2005. Various formulations of $f_{\mathrm{T}}$ and $f_{\mathrm{W}}$ generate a range of equilibrated soil carbon stores very similar to the six-fold range of global soil $\mathrm{C}$ achieved by CMIP5 models regardless of whether nutrient limitation is implemented. That is, the range in soil carbon in CMIP5 is likely the result of equilibration methods.

Implementing $\mathrm{N}$ and $\mathrm{P}$ limitations on plant productivity in the CASA-CNP ecosystem model better constrains the simulation of the historical response of the terrestrial $\mathrm{C}$ cycle irrespective of the $f_{\mathrm{T}}$ or $f_{\mathrm{W}}$ used because of the lack of response to post-1960 rapid increase in atmospheric $\mathrm{CO}_{2}$. However, in these simulations the initial carbon pool size is the main driver of the response of soil carbon to global warming. As the magnitude of the available substrate controls the sensitivity of $R_{\mathrm{h}}$ to changes in temperature and moisture, larger pools are more likely to deplete under global warming. Due to the size of soil carbon pools even small changes in forcing can lead to large $\mathrm{C}$ losses and drive the whole land $\mathrm{C}$ balance response to warming. Therefore, the wide range of responses in CMIP5 in terms of soil carbon may well be an artefact of the initialisation procedure used.

Based on our experiments, we recommend representing at least $\mathrm{CN}$ interactions in ESMs in order to capture the correct magnitude of historical land-atmosphere carbon fluxes and 
the response of the system to increasing atmospheric $\mathrm{CO}_{2}$. The other clear implication of our results is that a more concerted effort in how microbial decomposition processes are represented in ESMs is required. We need to address how equilibrium should be defined or constrained to match some estimates, how nutrients should be represented and how we develop these efforts with limited global databases of soil carbon.

\section{Supplementary material related to this article is available online at http://www.biogeosciences.net/10/ 7095/2013/bg-10-7095-2013-supplement.pdf.}

Acknowledgements. This work was supported by the Australian Research Council ARC grant DP110102618 and the ARC Centre of Excellence in Climate System Science grant CE110001028. Multiple model runs were made possible by the NCI National Facility at the Australian National University via the provision of computing resources to the ARC Centre of Excellence for Climate System Science.

Edited by: U. Seibt

\section{References}

Aber, J. D., Ollinger, S. V., and Driscoll, C. T.: Modeling nitrogen saturation in forest ecosystems in response to land use and atmospheric deposition, Ecol. Model., 101, 61-78, doi:10.1016/S0304-3800(97)01953-4, 1997.

Adair, E. C., Reich, P. B., Hobbie, S. E., and Knops, J. M. H.: Interactive Effects of Time, $\mathrm{CO}_{2}, \mathrm{~N}$, and Diversity on Total Belowground Carbon Allocation and Ecosystem Carbon Storage in a Grassland Community, Ecosystems, 12, 1037-1052, doi:10.1007/s10021-009-9278-9, 2009.

Allison, S. D., Wallenstein, M. D., and Bradford, M. A.: Soil-carbon response to warming dependent on microbial physiology, Nat. Geosci., 3, 336-340, doi:10.1038/ngeo846, 2010.

Bader, M., Hiltbrunner, E., and Körner, C.: Fine root responses of mature deciduous forest trees to free air carbon dioxide enrichment (FACE), Funct. Ecol., 23, 913-921, doi:10.1111/j.13652435.2009.01574.x, 2009.

Batjes, N. H.: Total carbon and nitrogen in the soils of the world, Eur. J. Soil Sci., 47, 151-163, doi:10.1111/j.13652389.1996.tb01386.x, 1996.

Boden, T. A., Marland, G., and Andres, R. J.: Global, Regional, and National Fossil-Fuel $\mathrm{CO}_{2}$ Emissions. Carbon Dioxide Information Analysis Center, Oak Ridge National Laboratory, US Department of Energy, Oak Ridge, Tenn., USA, doi:10.3334/CDIAC/00001_V2010, 2010.

Bonan, G. B. and Levis, S.: Quantifying carbon-nitrogen feedbacks in the Community Land Model (CLM4), Geophys. Res. Lett., 37, L07401, doi:10.1029/2010GL042430, 2010.

Bridgham, S. D., Megonigal, J. P., Keller, J. K., Bliss, N. B., and Trettin, C.: The carbon balance of north Amer- ican wetlands, Wetlands, 26, 889-916, doi:10.1672/02775212(2006)26[889:TCBONA]2.0.CO;2, 2006.

Canadell, J. G., Le Quéré, C., Raupach, M. R., Field, C. B., Buitenhuis, E. T., Ciais, P., Conway, T. J., Gillett, N. P., Houghton, R. A., and Marland, G.: Contributions to accelerating atmospheric $\mathrm{CO}_{2}$ growth from economic activity, carbon intensity, and efficiency of natural sinks, Proc. Natl. Acad. Sci., 104, 1886618870, doi:10.1073/pnas.0702737104, 2007.

Cox, P. M.: Description of the TRIFFID Dynamic Global Vegetation Model, Tech. Note 24, Met Off. Hadley Cent., Exeter, UK, 2001.

Cox, P. M., Betts, R. A., Jones, C. D., Spall, S. A., and Totterdell, I. J.: Acceleration of global warming due to carbon-cycle feedbacks in a coupled climate model, Nature, 408, 184-187, doi:10.1038/35041539, 2000.

Esser, G., Kattge, J., and Sakalli, A.: Feedback of carbon and nitrogen cycles enhances carbon sequestration in the terrestrial biosphere, Glob. Change Biol., 17, 819-842, doi:10.1111/j.13652486.2010.02261.x, 2011.

Exbrayat, J.-F., Pitman, A. J., Abramowitz, G., and Wang, Y.-P.: Sensitivity of net ecosystem exchange and heterotrophic respiration to parameterization uncertainty, J. Geophys. Res. Atmospheres, 118, 1640-1651, doi:10.1029/2012JD018122, $2013 \mathrm{a}$.

Exbrayat, J.-F., Viney, N. R., Frede, H.-G., and Breuer, L.: Using multi-model averaging to improve the reliability of catchment scale nitrogen predictions, Geosci. Model Dev., 6, 117-125, doi:10.5194/gmd-6-117-2013, 2013b.

Falloon, P., Jones, C. D., Ades, M., and Paul, K.: Direct soil moisture controls of future global soil carbon changes: An important source of uncertainty, Glob. Biogeochem. Cy., 25, GB3010, doi:201110.1029/2010GB003938, 2011.

Friedlingstein, P., Cox, P., Betts, R., Bopp, L., von Bloh, W., Brovkin, V., Cadule, P., Doney, S., Eby, M., Fung, I., Bala, G., John, J., Jones, C., Joos, F., Kato, T., Kawamiya, M., Knorr, W., Lindsay, K., Matthews, H. D., Raddatz, T., Rayner, P., Reick, C., Roeckner, E., Schnitzler, K.-G., Schnur, R., Strassmann, K., Weaver, A. J., Yoshikawa, C., and Zeng, N.: Climate-Carbon Cycle Feedback Analysis: Results from the $\mathrm{C}^{4}$ MIP Model Intercomparison, J. Clim., 19, 3337-3353, doi:10.1175/JCLI3800.1, 2006.

Goll, D. S., Brovkin, V., Parida, B. R., Reick, C. H., Kattge, J., Reich, P. B., van Bodegom, P. M., and Niinemets, Ü.: Nutrient limitation reduces land carbon uptake in simulations with a model of combined carbon, nitrogen and phosphorus cycling, Biogeosciences, 9, 3547-3569, doi:10.5194/bg-9-3547-2012, 2012.

Houghton, R.: Carbon Flux to the Atmosphere from Land-Use Changes: 1850-2005, in TRENDS: A Compendium of Data on Global Change, Carbon Dioxide Information Analysis Center, Oak Ridg., 2008.

Hurtt, G. C., Frolking, S., Fearon, M. G., Moore, B., Shevliakova, E., Malyshev, S., Pacala, S. W., and Houghton, R. A.: The underpinnings of land-use history: Three centuries of global gridded land-use transitions, wood-harvest activity, and resulting secondary lands, Global Change Biol., 12, 1208-1229, doi:10.1111/j.1365-2486.2006.01150.x, 2006.

Jain, A., Yang, X., Kheshgi, H., McGuire, A. D., Post, W., and Kicklighter, D.: Nitrogen attenuation of terrestrial carbon cycle response to global environmental factors, Glob. Biogeochem. Cy., 23, GB4028, doi:10.1029/2009GB003519, 2009. 
Jansson, P.-E. and Berg, B.: Temporal variation of litter decomposition in relation to simulated soil climate. Long-term decomposition in a Scots pine forest, V, Botany, 63, 1008-1016, doi:10.1139/b85-136, 1985.

Kirschbaum, M. U. F.: The temperature dependence of soil organic matter decomposition, and the effect of global warming on soil organic C storage, Soil Biol. Biochem., 27, 753-760, doi:10.1016/0038-0717(94)00242-S, 1995.

Kirschbaum, M. U. F.: Will changes in soil organic carbon act as a positive or negative feedback on global warming?, Biogeochemistry, 48, 21-51, 2000.

Kirschbaum, M. U. F.: Soil respiration under prolonged soil warming: are rate reductions caused by acclimation or substrate loss?, Glob. Change Biol., 10, 1870-1877, doi:10.1111/j.13652486.2004.00852.x, 2004.

Knorr, W., Prentice, I. C., House, J. I., and Holland, E. A.: Longterm sensitivity of soil carbon turnover to warming, Nature, 433, 298-301, doi:10.1038/nature03226, 2005.

Koster, R. D., Guo, Z., Yang, R., Dirmeyer, P. A., Mitchell, K., and Puma, M. J.: On the Nature of Soil Moisture in Land Surface Models, J. Clim., 22, 4322-4335, doi:10.1175/2009JCLI2832.1, 2009.

Le Quéré, C., Raupach, M. R., Canadell, J. G., Marland, G., Bopp, L., Ciais, P., Conway, T. J., Doney, S. C., Feely, R. A., Foster, P., Friedlingstein, P., Gurney, K., Houghton, R. A., House, J. I., Huntingford, C., Levy, P. E., Lomas, M. R., Majkut, J., Metzl, N., Ometto, J. P., Peters, G. P., Prentice, I. C., Randerson, J. T., Running, S. W., Sarmiento, J. L., Schuster, U., Sitch, S., Takahashi, T., Viovy, N., van der Werf, G. R., and Woodward, F. I.: Trends in the sources and sinks of carbon dioxide, Nat. Geosci., 2, 831-836, doi:10.1038/ngeo689, 2009.

Luo, Y., Wan, S., Hui, D., and Wallace, L. L.: Acclimatization of soil respiration to warming in a tall grass prairie, Nature, 413, 622-625, doi:10.1038/35098065, 2001.

Luo, Y., Su, B., Currie, W. S., Dukes, J. S., Finzi, A., Hartwig, U., Hungate, B., Mc Murtrie, R. E., Oren, R., Parton, W. J., Pataki, D. E., Shaw, M. R., Zak, D. R., and Field, C. B.: Progressive Nitrogen Limitation of Ecosystem Responses to Rising Atmospheric Carbon Dioxide, BioScience, 54, 731, doi:10.1641/00063568(2004)054[0731:PNLOER]2.0.CO;2, 2004.

McCarthy, H. R., Oren, R., Johnsen, K. H., Gallet-Budynek, A., Pritchard, S. G., Cook, C. W., LaDeau, S. L., Jackson, R. B., and Finzi, A. C.: Re-assessment of plant carbon dynamics at the Duke free-air $\mathrm{CO}_{2}$ enrichment site: interactions of atmospheric $\left[\mathrm{CO}_{2}\right]$ with nitrogen and water availability over stand development, New Phytol., 185, 514-528, doi:10.1111/j.14698137.2009.03078.x, 2010.

Menge, D. N. L., Hedin, L. O., and Pacala, S. W.: Nitrogen and Phosphorus Limitation over Long-Term Ecosystem Development in Terrestrial Ecosystems, Plos One, 7, e42045, doi:10.1371/journal.pone.0042045, 2012.

Moyano, F. E., Vasilyeva, N., Bouckaert, L., Cook, F., Craine, J., Curiel Yuste, J., Don, A., Epron, D., Formanek, P., Franzluebbers, A., Ilstedt, U., Kätterer, T., Orchard, V., Reichstein, M., Rey, A., Ruamps, L., Subke, J.-A., Thomsen, I. K., and Chenu, C.: The moisture response of soil heterotrophic respiration: interaction with soil properties, Biogeosciences, 9, 1173-1182, doi:10.5194/bg-9-1173-2012, 2012.
Norby, R. J., Warren, J. M., Iversen, C. M., Medlyn, B. E., and McMurtrie, R. E.: CO2 enhancement of forest productivity constrained by limited nitrogen availability, Proc. Natl. Acad. Sci., 107, 19368-19373, doi:10.1073/pnas.1006463107, 2010.

Phipps, S. J., Rotstayn, L. D., Gordon, H. B., Roberts, J. L., Hirst, A. C., and Budd, W. F.: The CSIRO Mk3L climate system model version 1.0 - Part 1: Description and evaluation, Geosci. Model Dev., 4, 483-509, doi:10.5194/gmd-4-483-2011, 2011.

Prentice, I. C., Farquhar, G. D., Fasham, M. J. R., Goulden, M. L., Heimann, M., Jaramillo, V. J., Kheshgi, H. S., Le Quéré, C., Scholes, R. J., and Wallace, D. W. R.: The carbon cycle and atmospheric carbon dioxide, in: Climate Change 2001: The Scientific Basis, edited by: Houghton, J. T., Ding, Y., Griggs, D. J., Noguer, M., van der Linden, P. J., Dai, X., Maskell, K., and Johnson, C. A.: Contribution of Working Group I to the Third Assessment Report of the Intergovernmental Panel on Climate Change, Cambridge University Press, Cambridge, USA, 183-237, 2001.

Rotstayn, L. D., Jeffrey, S. J., Collier, M. A., Dravitzki, S. M., Hirst, A. C., Syktus, J. I., and Wong, K. K.: Aerosol- and greenhouse gas-induced changes in summer rainfall and circulation in the Australasian region: a study using single-forcing climate simulations, Atmos. Chem. Phys., 12, 6377-6404, doi:10.5194/acp-126377-2012, 2012.

Sarmiento, J. L., Gloor, M., Gruber, N., Beaulieu, C., Jacobson, A. R., Mikaloff Fletcher, S. E., Pacala, S., and Rodgers, K.: Trends and regional distributions of land and ocean carbon sinks, Biogeosciences, 7, 2351-2367, doi:10.5194/bg-7-2351-2010, 2010.

Schmidt, M. W. I., Torn, M. S., Abiven, S., Dittmar, T., Guggenberger, G., Janssens, I. A., Kleber, M., Kögel-Knabner, I., Lehmann, J., Manning, D. A. C., Nannipieri, P., Rasse, D. P., Weiner, S., and Trumbore, S. E.: Persistence of soil organic matter as an ecosystem property, Nature, 478, 49-56, doi:10.1038/nature10386, 2011.

Sitch, S., Huntingford, C., Gedney, N., Levy, P. E., Lomas, M., Piao, S. L., Betts, R., Ciais, P., Cox, P., Friedlingstein, P., Jones, C. D., Prentice, I. C., and Woodward, F. I.: Evaluation of the terrestrial carbon cycle, future plant geography and climate-carbon cycle feedbacks using five Dynamic Global Vegetation Models (DGVMs), Glob. Change Biol., 14, 2015-2039, doi:10.1111/j.1365-2486.2008.01626.x, 2008.

Sokolov, A. P., Kicklighter, D. W., Melillo, J. M., Felzer, B. S., Schlosser, C. A., and Cronin, T. W.: Consequences of Considering Carbon-Nitrogen Interactions on the Feedbacks between Climate and the Terrestrial Carbon Cycle, J. Clim., 21, 37763796, doi:10.1175/2008JCLI2038.1, 2008.

Tarnocai, C., Canadell, J. G., Schuur, E. a. G., Kuhry, P., Mazhitova, G., and Zimov, S.: Soil organic carbon pools in the northern circumpolar permafrost region, Glob. Biogeochem. Cy., 23, GB2023, doi:10.1029/2008GB003327, 2009.

Taylor, K. E., Stouffer, R. J., and Meehl, G. A.: An Overview of CMIP5 and the Experiment Design, Bull. Am. Meteorol. Soc., 93, 485-498, doi:10.1175/BAMS-D-11-00094.1, 2012.

Thornton, P. E., Lamarque, J.-F., Rosenbloom, N. A., and Mahowald, N. M.: Influence of carbon-nitrogen cycle coupling on land model response to $\mathrm{CO}_{2}$ fertilization and climate variability, Glob. Biogeochem. Cy., 21, GB4018, doi:10.1029/2006GB002868, 2007.

Todd-Brown, K. E. O., Hopkins, F. M., Kivlin, S. N., Talbot, J. M., and Allison, S. D.: A framework for representing microbial de- 
composition in coupled climate models, Biogeochemistry, 109, 19-33, doi:10.1007/s10533-011-9635-6, 2012.

Todd-Brown, K. E. O., Randerson, J. T., Post, W. M., Hoffman, F. M., Tarnocai, C., Schuur, E. A. G., and Allison, S. D.: Causes of variation in soil carbon simulations from CMIP5 Earth system models and comparison with observations, Biogeosciences, 10, 1717-1736, doi:10.5194/bg-10-1717-2013, 2013.

Vitousek, P. M. and Howarth, R. W.: Nitrogen Limitation on Land and in the Sea: How Can It Occur?, Biogeochemistry, 13, 87$115,1991$.

Vitousek, P. M., Porder, S., Houlton, B. Z., and Chadwick, O. A.: Terrestrial phosphorus limitation: mechanisms, implications, and nitrogen-phosphorus interactions, Ecol. Appl., 20, 5-15, doi:10.1890/08-0127.1, 2010.

Wang, Y. P., Law, R. M., and Pak, B.: A global model of carbon, nitrogen and phosphorus cycles for the terrestrial biosphere, Biogeosciences, 7, 2261-2282, doi:10.5194/bg-7-2261-2010, 2010.

Wang, Y. P., Kowalczyk, E., Leuning, R., Abramowitz, G., Raupach, M. R., Pak, B., Gorsel, E., and van and Luhar, A.: Diagnosing errors in a land surface model (CABLE) in the time and frequency domains, J. Geophys. Res., 116, G01034, doi:10.1029/2010JG001385, 2011.

Yang, X., Wittig, V., Jain, A. K., and Post, W.: Integration of nitrogen cycle dynamics into the Integrated Science Assessment Model for the study of terrestrial ecosystem responses to global change, Glob. Biogeochem. Cy., 23, GB4029, doi:10.1029/2009GB003474, 2009.
Zaehle, S. and Friend, A. D.: Carbon and nitrogen cycle dynamics in the O-CN land surface model: 1. Model description, site-scale evaluation, and sensitivity to parameter estimates, Glob. Biogeochem. Cy., 24, GB1005, doi:10.1029/2009GB003521, 2010.

Zaehle, S., Friedlingstein, P., and Friend, A. D.: Terrestrial nitrogen feedbacks may accelerate future climate change, Geophys. Res. Lett., 37, L01401, doi:10.1029/2009GL041345, 2010a.

Zaehle, S., Friend, A. D., Friedlingstein, P., Dentener, F., Peylin, P., and Schulz, M.: Carbon and nitrogen cycle dynamics in the $\mathrm{O}-\mathrm{CN}$ land surface model: 2 . Role of the nitrogen cycle in the historical terrestrial carbon balance, Glob. Biogeochem. Cycles, 24, GB1006, doi:10.1029/2009GB003522, 2010 b.

Zak, D. R., Pregitzer, K. S., Kubiske, M. E., and Burton, A. J.: Forest productivity under elevated $\mathrm{CO} 2$ and $\mathrm{O} 3$ : positive feedbacks to soil $\mathrm{N}$ cycling sustain decade-long net primary productivity enhancement by $\mathrm{CO}_{2}$, Ecol. Lett., 14, 1220-1226, doi:10.1111/j.1461-0248.2011.01692.x, 2011.

Zhang, Q., Wang, Y. P., Pitman, A. J., and Dai, Y. J.: Limitations of nitrogen and phosphorous on the terrestrial carbon uptake in the 20th century, Geophys. Res. Lett., 38, L22701, doi:10.1029/2011GL049244, 2011.

Zhang, Q., Pitman, A. J., Wang, Y. P., Dai, Y. J., and Lawrence, P. J.: The impact of nitrogen and phosphorous limitation on the estimated terrestrial carbon balance and warming of land use change over the last 156 yr, Earth Syst. Dynam., 4, 333-345, doi:10.5194/esd-4-333-2013, 2013. 